\title{
20th Century Accounts of American Citizenship
}

\author{
Jed Donoghue \& Bob White \\ University of Tasmania, Australia \\ Correspondence: Jed Donoghue, University of Tasmania, Australia \\ Received: December 30, 2013 Accepted: January 16, 2014 Available online: February 11, 2014 \\ doi:10.11114/ijsss.v2i2.311 \\ URL: http://dx.doi.org/10.11114/ijsss.v2i2.311
}

\begin{abstract}
Accounts of citizenship by Presidents of the American Political Science Association (APSA) are examined through Mannheim's sociology of knowledge. We use Marshall as a platform to reconceptualise the dynamics of Mannheim's three incommensurable 'thought styles': one liberal; one conservative; and one dialectically social. We suggest on this basis that American political citizenship in the twentieth century entails three incompatible but concurrent 'thought styles', that involve a triple helix of political rationalities (see White and Donoghue 2003).

The model is tested in a longitudinal study of 'citizenship and democracy' in regular social scientific usage. The empirical material comprises the presidential addresses to the American Political Science Association (APSA) published in the American Political Science Review (APSR) from 1906 to 1997. The findings suggest that the addresses by the presidents of the Political Science Association of America invoke intertwining rationalities that relate twentieth century citizenship to classical political discourses.
\end{abstract}

Keywords: Citizenship, Presidential Addresses, American Political Science

\section{Introduction}

Accounts of citizenship by Presidents of the American Political Science Association are examined through Mannheim's sociology of knowledge. In the introductory section on citizenship the paper will stress that citizenship is essentially contestable; that it is component of modern democracy and that it involves trinary orderings to accommodate tensions. Marshall's tripartite models of citizenship provide a point of departure: the widely discussed claim in his early work that civil, political and social rights emerged sequentially and the less noted account of democratic-welfare-capitalist tensions in the 'hyphenated society'.

The paper will briefly sketch Marshall's arguments and then use them to reconceptualise the dynamics of Mannheim's three incommensurable 'thought styles': one liberal; one conservative; and one dialectically social. The paper suggests on this basis that American political citizenship is seen as entailing three mutually incompatible 'thought styles' that involve a triple helix of political rationalities (see White and Donoghue 2003). The paper suggests that the Presidents' accounts invoke the ragged intertwining of rationalities, and in the concluding discussion the citizenship will be linked to modern themes in the study of politics.

'Citizenship' is a key marker of participation and membership. It has never proved amenable to exhaustive and comprehensive definition. Like other central social scientific concepts, it is essentially contestable, in that its meanings emerge in disputed and recursive use (Gallie 1964, Isin 2002). That has been a feature throughout all the accounts of citizenship written since Aristotle's pragmatic allowance for the difficulty: "[w] hat effectively distinguishes the citizen proper from all others is his participation in giving judgement and in holding office" (Politics 1962: 22). Since that simply shifts the issue to what 'participation' means, and since accounts of 'participation' are always entangled in politico-moral claims, the definitional problem remains. Marshall's version, that citizenship is "a status bestowed on those who are full members of a community" (1950: 28), leaves the question as open as did Aristotle's, for while 'membership' may be formally defined, 'community' retains all the uncertainty of its popular use. Contestable concepts can yield relatively fixed points in what would otherwise be an impossible churn, and they are also points of departure.

Writers on citizenship often take Marshall's 1950's tripartite model of the successive stages of civil, political and social rights as a point of departure rather than as a given. One effect of the paradigmatic functioning of that model, however, has been the return of the 'economic man' who has been striding through so much of the social analysis of the last two hundred years. To take civil, political and social as analytically distinct and as historically successive is already to 
privilege the rationality, which defines economic man. Writers on citizenship have often included a 'cultural' element as a replacement for what is inevitably lost in this analytical privileging; that was Parsons' solution. Another solution is to take Marshall's civil, political and social moments as co-emergent rather than as successive.

Turner stressed those difficulties in his note on Mannheim's account of the intellectuals (1993: 170), where he revisited the problem of how analysts can make authoritative claims about social life when their own work is enmeshed in that life; if social analysis is as existentially shaped as other effects of broader processes then the basis of authority is uncertain. But his response to the problem is characteristic of social science; he noted it and moved on. When, for example, he held that it "is conceptually parsimonious to think of three types of resource: economic, cultural and political" (Turner 1997: 7), he seemed to locate his argument beyond the economic, cultural and political; presuming the analytical detachment he had earlier noted as problematic.

\section{Sociology of Knowledge}

Mannheim placed a triadic emphasis on the tension between incompatible ways of knowing. He had set the pattern in his earliest work in the sociology of knowledge, where like Scheler, he pointed to what was lost in epistemological accounts of knowledge. To accommodate the psychological, ontological and logical pre-commitments elided in the 'either / or' of strict analysis, he argued that knowledge emerged as a relation between the knower (subject), the known, and the to-be-known (object), where the subject was always an intersubject, the known was always selectively drawn from tradition, and the to-be-known was then always historically contingent.

"Every epistemological systematization", he held, "is based upon this triad, and every conceivable formulation of the problem of knowledge is given by these three terms in some combination" (Mannheim 1922: 58).

For all the limits of epistemology, Mannheim held that the self-relativisation in it was genealogically crucial to the sociology of knowledge. The individualising trend from Descartes' cogito to Kant's account of the subject gave one element in any knowledge under study. It had been followed, interactively, by the attention to collective subjects in Marxist ideological analysis and by the emergence of 'the social' as an "ontological 'terminus' of the motion transcending theoretical immanence" (Mannheim 1925: 68). Those three genealogical moments Ire permanently coexistent rather than successive and Ire fused in the 'total relativisation' of the sociology of knowledge.

Mannheim likewise depicted it as requiring three types of methods (1921-2; 1925). It should be 'scientific', for although positivism had remained at "a relatively primitive level" in the bourgeois and proletarian nuances of Durkheimian work and of materialism respectively, it remained valuable, ironically, for its metaphysics of "essential contact with reality" (Mannheim 1925: 76). The sociology of knowledge should be hermeneutically focused on the weltanschauung, or unified complex of meanings prevailing at a given time (Mannheim 1921-2).

Mannheim linked his sociology of knowledge to political movements. As seen in the variant links between theory and practice developed interdependently in the emergence of liberalism, socialism and conservatism and applied interdependently in the academy, the agonism of knowledge and its study was entangled in broader conflicts (Mannheim 1828a: 248-50; 1929: 117-46; 1927). The sociology of knowledge was to be a 'dynamic synthesis' of the tendencies summarised in the three movements.

Mannheim also called into question the 'progress' implied or stated in theories of 'stages'. They stressed instead the continuing interaction between different ways of knowing, or between what Mannheim called 'thought styles' (e.g. 1927). The structure of their arguments was as crucial as what they argued. The trinary ordering they used is parsimonious, being the next simplest way of classifying beyond the 'either/or' and 'before/after' found in analytically linear accounts of 'progress'. At the same time it leaves in play the knowledge-politics preempted in those accounts.

Mannheim had come to see intellectuals as uniquely authoritative. Despite their varied backgrounds, he saw them as relatively united by an education that 'tends to suppress differences of birth, status, profession and wealth' (Mannheim 1929: 155). Losing the 'illusion that there is only one way of thinking' (Mannheim 1936: 12), they had 'a maximum opportunity to test and employ the socially available vistas and to experience their inconsistencies' (Mannheim 1929: 106). By collectively agreeing on those vistas, and by working in political parties and academia, they could fulfil 'their mission as the predestined advocate of the intellectual interests of the whole' (Mannheim 1929: 158).

After the First World War, Great Depression, rise of fascism and impending second World War, the risks of social dissolution were such that 'the successful organization of society cannot be left to chance' (Mannheim 1935: 7). Intellectuals had to save liberal democracy from itself. Planning was needed for the renewal of a spiritual sense in the body politic, and a planned society would require experts 'somehow similar to the priests, whose task it will be to watch that certain basic standards are established and maintained' (Mannheim 1943: 119). Through 'social techniques', such as the political propaganda or reconditioning, 'groups with determined political will, equipped with the necessary 
psychological and sociological knowledge' could according to Mannheim educate the masses in their duties (1937: 530-42).

\section{Political Speeches}

Conversation-analysts have shown in studies of political speeches and everyday conversations that the rhetorical devices most successful in eliciting applause or agreement are antitheses and triply structured lists (e.g. Atkinson 1984; Heritage and Greatbatch 1986). Antithesis always entails partisan foreclosure. It is always a means of the hierarchical ranking so widely associated with binary categories. Triple structured lists are more complex. To order by threes is to suggest that more cases could always be mentioned, and thus to stress the generality of the instances listed. But three-part lists also produce an effect of climactic closure (Potter 1995: 195-7) in a pattern, which appears to hold cross-culturally, conversationalists and audiences are cued to respond to them.

Simmel's discussion of the interactions in small groups is canonical. His claim that "the triad is a structure completely different from the dyad, but not, on the other hand, specifically distinguished from groups of four or more members" matches the generality of triply structured lists, and his observation that the "appearance of the third party indicates transition, conciliation, and abandonment of absolute contrast" gives the same shift from fixity to fluidity as in that from binary to trinary orderings (Simmel 1908: 141, 145). Recalling the repetition across scale from conversations to political speeches, Caplow extended Simmel's analysis of small groups to a claim that triads are "the building blocks of which all social organizations are constructed" (1968: 1). It is commonly argued that binary ordering is a 'deep structure' in human organisation (e.g. Maybury-Lewis and Almagor 1989), and it may be that the same is true of the trinary, at least in Indo-European cultures (e.g. Dumezil 1968). To the double helix of genetic evolution there corresponds a triple helix of political potential.

To allow for the essential contestability of work in the social sciences, we follow White's $(2002,6)$ rhetorically topical definition of a 'concept' as "a recurrent pattern of polymorphous, situated and value-charged discursive strategies in disciplinary writing". This emphasises the inevitability of disputes over what concepts mean and how they should be used. It is a form of Mannheim's 'dynamic synthesis' of what is always political. On that basis, we understand 'citizenship' as a recursive effect of disputes over participation, membership and belonging, where those disputes entail the three forms of political rationality which Mannheim variously suggested: the linearly individual rationality of liberalism; the dialectically collective rationality of socialism; and the collective arationality of conservatism (see White and Donoghue 2003).

This means that we do not have to move far from Aristotle's definition of citizenship as "participation in giving judgement and in holding office" (Politics 1962: 22), or from the echo of it in Marshall's definition as "a status bestowed on those who are full members of a community" (1950: 28). We simply focus on the contesting of 'participation' and 'membership'. We illustrate our model of conflicting rationalities through a content analysis of the use of 'citizenship' in presidential addresses to the 'modern discipline' of the American Political Science Association. Specifically, we expect that the presidents' use of the concept will be linked only contingently to the shifts in inclusiveness suggested under Marshall's own models, and that liberal/individual accounts of citizenship will be interwoven with more collective and conservative versions.

Following White and Donoghue (2003) we argue that Mannheim's sociology of knowledge allows a re-reading of modern American citizenship, which can accommodate difficulties in the field. As we noted earlier, something must be held constant in the study of social change. We use the sociology of knowledge to hold constant the 'how' of disputes over citizenship rather than the 'what'. Instead of Turner's 'three types of resource' we focus on three types of political rationality; liberalism, socialism and conservativism.

\section{Presidential Addresses}

Presidential addresses to the APSA are particularly well suited to the purposes outlined here. While any set of texts devoted to political analysis would serve, so long as it was systematically chosen from across a given period, the addresses have advantages over such other forms as articles in journals, textbooks, monographs, or books written for the general public, advantages which follow from their generic functioning and from the fact that they are American.

That the addresses are by Americans is important. If the professional social scientist is the "most revealing symptom of modernity" (Haskell 1977: vii), then the effect should be strongest in the United States. American political science was long been the largest and most institutionalised branch of the discipline, with more than 15,000 members residing in over 80 countries worldwide, the American Political Science Association is the world's largest professional organization for the study of politics. Furthermore, it has been commonly remarked that the development of citizenship in the United States does not fit Marshall's model (see Turner 1993), so it provides a stronger test than British or European political science material. 
Generically, the addresses fulfill several functions simultaneously. As the highest formal honour in American political science, the APSA's presidency is conferred on those whose work the most established members of the discipline have judged the most eminent, and the address then allows each president to expand on the methods and broader relevance of their substantive area, which is therefore sanctioned as central to the discipline; this is the presidential address as exemplary political science, formally recognized. Presented at the annual meeting to an audience of political scientists and guests from government, business and other disciplines, the address is also an oratory state-of-the-union speech, directing attention to failures and successes in the discipline at large; this is the presidential address about exemplary political science, formally justified. Delivered, finally, as a ceremonial feature of the meeting, and routinely published in the APSR, the address is a focus of disciplinary ritual, with all the re-affirmation of collectivity that that implies; this is the presidential address for exemplary political science, formally celebrated. The disciplinary and participatory membership, which is generically recognized, policed and celebrated in the addresses is then simultaneously a smaller scale version of the citizenship and democracy that we see as emergent from conflicting rationalities and a vehicle for access to it.

On that basis, we have examined the presidential addresses to the APSA from 1906 to 1997, which also avoids any end of century or millennium effects. The series starts with the first address, Goodnow's foundation speech did not appear in the Review, which was not launched until two years after the Association was formed. No address was prepared in 1918, when the annual meeting was cancelled amid wartime train travel restrictions, and there are three missing cases; if addresses were delivered at the APSA meetings of 1920, 1930 and 1952, they were not published in the normal sequence.

\section{Analysis}

The first step in the study of the addresses is a minimalist content analysis. We were interested as much in the presidents' casual and taken-for-granted references to citizenship as in any direct focus on the issue, we take the frequency of the use of 'citizen', and of such derivatives as 'citizenry' or 'citizenship', as a marker of the issue's salience. We take the use of 'participation' as an index of attention to that Marshallian theme, and similarly we use 'individual', 'society' and 'community/culture' as political markers of the three different rationalities, which the presidents invoke.

In this phase of the study, we are not interested in the 'meanings' that the presidents impute to 'citizen' or to the other concepts. To code meanings would be to preempt both the possibility that contradictory meanings are being advanced simultaneously and the essential contestability that we see at issue. We want only to show the co-presence of the concepts in the Presidential addresses. Having scanned the addresses into electronic form, we counted every occurrence of our selected terms, regardless of context. The numbers of presidents using each term are shown in Table 1 below.

To show trends, we divided the eighty-eight accounts of the study into ten roughly equal periods, and derived mean scores for each period. To enable comparison between addresses, we have standardised all the counts as occurrences per thousand words. We show first the use of 'citizen' and 'participation' between 1906 and 1997 in Figure 1.

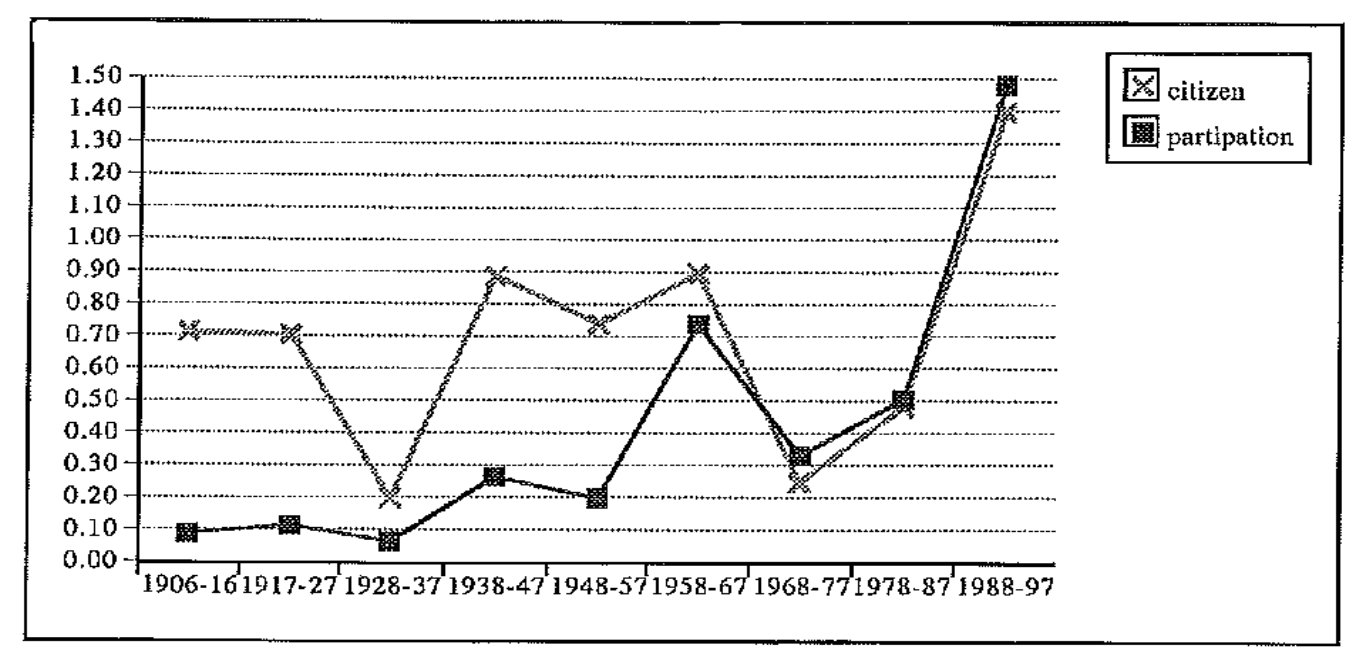

Figure 1. Use of Citizen \&. Participation 1906 - 1997

From 1960 to the end of the twentieth century the use of 'participation' mirrors the frequency of the usage of 'citizen' very closely. Since the 1960s participation was used to indicate not just political activity but a range of social, cultural 
and economic endeavors. Whereas, the increasing use of 'participation' and 'citizen' parallel each other since the 1960 's, the use of the word 'membership' appears to decline. For a finer grained picture of what 'citizenship' entailed, we examined it in relation to the shifting relations between 'citizen', 'democracy' and 'vote' in Figure 2.

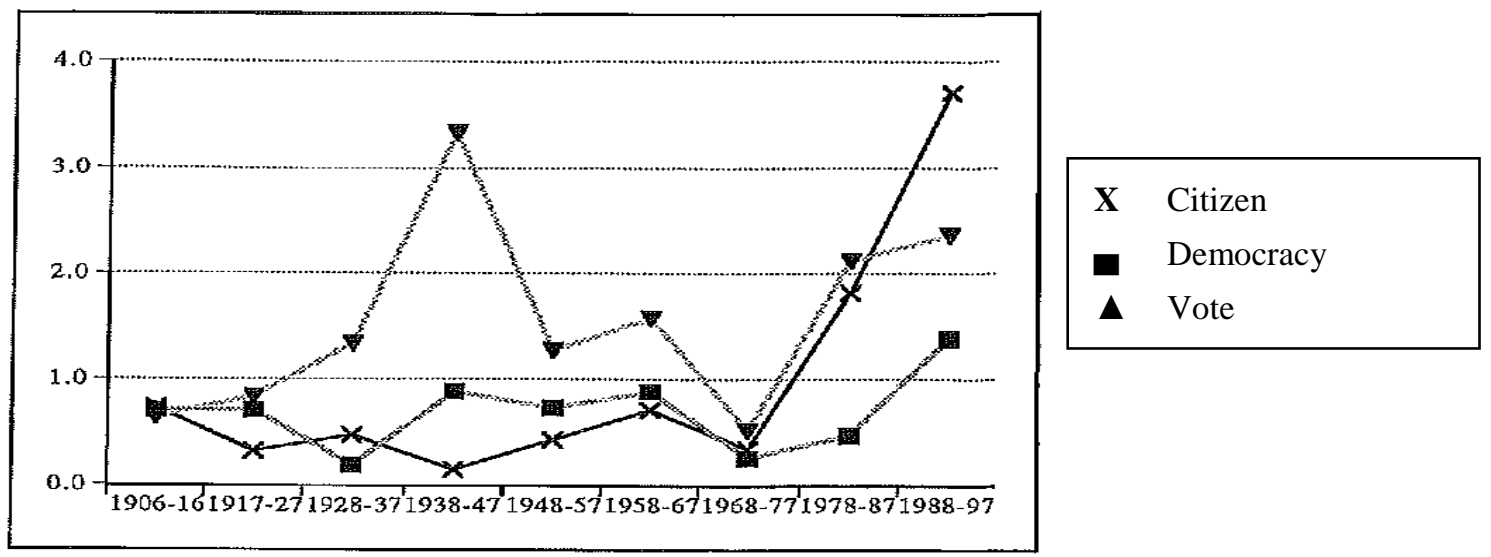

Figure 2. Use of Citizen, Democracy \& Vote 1906-1997

Although the late peak here is consistent with recent attention to 'citizenship', the overall pattern is hardly a 'trend'. Nor can it be fitted neatly to shifts in American political life. The rough consistency from the first two periods to the fourth, fifth and sixth corresponds with extension of the franchise, first to women and then to African Americans due to the civil rights movement, and in wartime, when American intervention was decisive in making Europe safe for western democracies. But the troughs during the Depression years of 1928-37 and from the late 1960s to the late 1980s are intriguing. Both low points were or included tumultuous times culturally and politically, yet the Presidents' responses to them were relatively detached from the concept of 'citizenship'.

The results shown in Figure 3 indicate the use of individual', 'society' and 'community /culture' by the Presidents of the APSA. The relevance of the 'individual' declines as expected between the two World Wars in contrast to the increased focus on community /culture. In post WW2 America both concepts are increasingly used throughout the 1960 s and 1970s, until the 1980s when community/ culture suddenly declines. The term society seems to counterbalance the use of individual and community /culture, until the end of the century when the individual appears to triumph over other forms of association and goes 'bowling' alone (Putnam 2000).

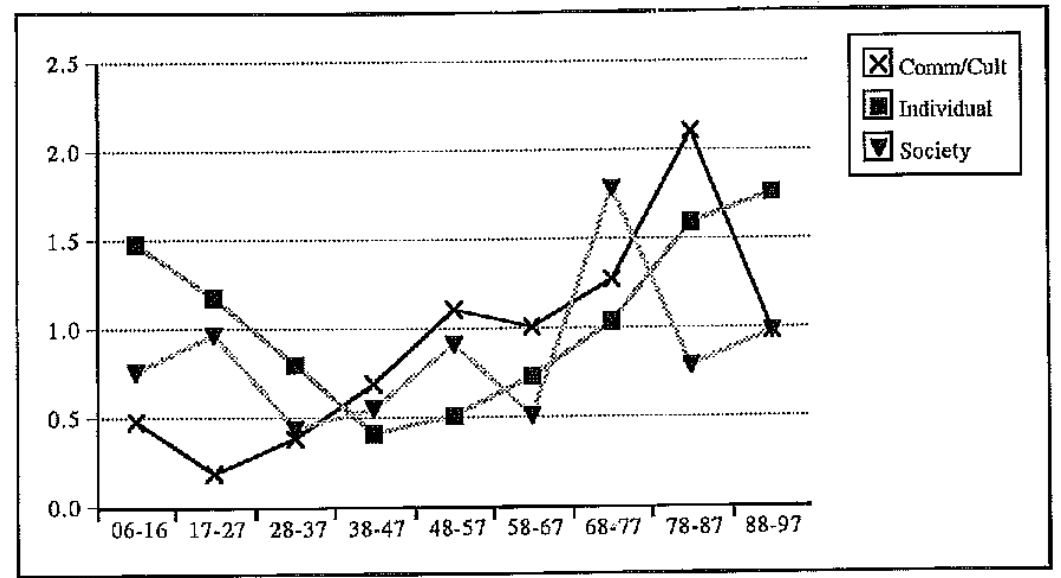

Figure 3. Use of Individual, Society \& Community/Culture

\section{Discussion}

Mannheim (1952: 184-6) allows us to show 'that a certain style of thought, an intellectual standpoint, is encompassed with a system of attitudes which in turn can be seen to be related to a certain economic and power system'. Mannheim realized that "different social strata, then do not "produce different systems of ideas" (Weltanschauugen) in a crude, materialistic sense - in the sense in which lying ideologies can be "manufactured" - they "produce" them, rather, in the sense that social groups emerging within the social process are always in a position to project new directions of that "intentionally".

For Mannheim (1952: 189) 'shifts in social reality are the underlying cause of shifts in theoretical systems'. By developing Mannheim's 'dynamic standpoint' we argue that the main task of a sociology of knowledge in relation to 
citizenship consists in specifying, for each temporal cross-section of the historical process, the various systematic intellectual standpoints on which the thinking of creative individuals and groups are based. Once intellectual standpoints are identified the different 'trends of thought should not be confronted like positions in a mere theoretical debate' (ibid.). The sociological task according to Mannheim (1952) 'consists in finding the social strata making up the intellectual strata in question': it is only in terms of the role of these strata within the overall process, in terms of their attitudes towards the emerging new reality, that we can define the fundamental aspirations and world postulates existing at a given time which can absorb already existing ideas and methods and subject them to a change of function - not to speak of newly created forms (op. cit.: 189).

Hegel's conservative 'dialectical method' provides an obvious sociological and historical example of how an idea is re-interpreted and modified. Marx changed Hegel's meaning and function of 'dialectics' to suit the social conditions and future aspirations of the proletariat. In terms of citizenship we would argue that Mannheim allows us to reinterpret and modify Marshall's civil/capitalist, political/democratic and social/welfare elements and introduce arational, collective and cultural factors into the paradigm. The tensions in contemporary citizenship reflect the dynamics of new, national and global social movements based on demands, for animal, economic, and environmental rights. To stretch Marshall's under-developed evolutionary metaphor, we could even say that the contested emergence of citizenship rights entails a spiral of thought-styles comparable to the (double) helix proposed by Crick and Watson (1953).

The historical and trans-situational recurrence of triadic ordering suggests something in human nature, that in a way that bridges the Great Divide between humans and non-humans. It is also consistent with contemporary neo-Darwinian accounts of human evolution that interested Mannheim's student Elias (Mennell and Goudsblom 1998: 12). The egoistic, nepotistic and altruistic dynamics that have been identified (see Boehm 2001), are permanently in tension, and match the individual, group-specific and diffusely collective forms of political rationality we have suggested in relation to American citizenship.

\section{Conclusion}

Accounts of citizenship by Presidents of the American Political Science Association (APSA) are examined using Mannheim's sociology of knowledge. We suggest that citizenship is essentially contestable; that it is component of modern democracy and that it involves trinary orderings to accommodate tensions. We order APSA President's intellectual views in terms of their 'emerging reality' to highlight the claims made at particular times during the century. The President's speeches reflect ideas and aspirations but the claims are also subject to a change of function or emphasis depending on immediate social issues and concerns. Domestic cultural, economic and political ideas and concerns are also impacted by two World Wars and global depressions.

The increased focus on the individual in American political life since the end of World War 2 perhaps reflects the growth of American prestige and prosperity. The counter culture and civil rights movement bloomed during the 1960s and 1970s but faded after the oil shock in the 1980s. The individual triumphed at the end of the twentieth century, as 'he' did it the end of the nineteenth century, but this time the individual was no longer necessarily a single male, the individual could now be an independent female. The helix has returned to a familiar position but at a different point of cultural and political departure.

We suggest that addresses by the presidents of the Political Science Association of America invoke different rationalities that relate twentieth century citizenship to classical political discourses or 'thought styles': one liberal; one conservative; and one dialectically social. The primacy of the liberal individual has been challenged in the first decade of the 21 st century by conservative demands for stronger forms of membership due to fears of terrorism and homeland security needs. We suggest that political contestation during the course of the $21^{\text {st }}$ century will be argued in terms of these classical political 'thought styles' that are mobilized by intellectuals reacting to the cultural, economic and political events of the day.

\section{References}

Aristotle. (1962). The Politics T. A. Sinclair and Trevor J. Saunders (eds, trans) London: Penguin.

Atkinson, M. (1984). Our Masters' Voices: The Language and Body Language of Politics London: Methuen.

Caplow, T. (1968). Two against one: coalitions in triads Englewood Cliffs NJ: Prentice-Hall.

Dumezil, G. (1968). Mythe et epopee: L'ideologie de trois functions dans les epopees des peuples indo-europeens Paris: Gallimard.

Gallie, W. B. (1964/1968). Philosophy and the Historical Understanding. second edition New York: Schocken.

Haskell, T. L. (1977). The Emergence of Professional Social Science: The American Social Association and the Nineteenth-Century Crisis of Authority. Urbana: University of Illinois Press. 
Heritage, J., \& David, G. (1986). 'Generating Applause: A Study of Rhetoric and Response at Party Political Conferences' American Journal of Sociology, 92, 110-57. http://dx.doi.org/10.1086/228465

Isin, E. F. (2002). Being Political: Genealogies of Citizenship, University of Minnesota Press, Minneapolis.

Mannheim, K. (1925). 'The Problem of a Sociology of Knowledge' in From Karl Mannheim Kurt Wolff (ed.) New York: Oxford University Press: 59-115.

Mannheim, K. (1937). 'On the diagnosis of our time', in K. Wolff (ed.) From Karl Mannhiem, New York: Oxford University Press, pp. 526-42.

Mannheim. (1943). [1947] Diagnosis of Our Times: Wartime Essays of a Sociologist, London: Kegan Paul, Trench, Trubner \& Co.

Mannheim, K. (1952). Essays on the Sociology of Knowledge, London: Routledge \& Kegan Paul.

- (1927). 'Conservative Thought' in From Karl Mannheim Kurt Wolff (ed.) New York: Oxford University Press: 132-222.

- (1929/1936). Ideology and Utopia: An Introduction to the Sociology of Knowledge Louis Wirth and Edward Shils (trans) San Diego: Harvest.

Marshall, T. H. (1950/1973). Class, Citizenship and Social Development Westport CT: Greenwood.

- (1972). 'Value-Problems of Welfare Capitalism' in The Right to Welfare and other essays New York: Free Press: $104-22$

- (1981). 'Afterthought on 'Value Problems of Welfare-Capitalism': The 'Hyphenated Society' in The Right to Welfare and other essays New York: Free Press: 123-36.

Maybury-Lewis, D., \& Uri, A. (eds) (1989). The Attraction of Opposites: Thought and Society in the Dualistic Mode Ann Arbor MI: University of Michigan Press.

Potter, J. (1995). Representing Reality: Discourse, Rhetoric and Social Construction London: Sage.

Putnam, R. (2000). Bowling Alone: The Collapse and Revival of American Community. New York: Simon \& Schuster.

Scheler, M. (1921/1970). 'On the positivistic philosophy of the history of knowledge and its law of three stages' in James E. Curtis and John W. Petras (eds) The Sociology of Knowledge: A Reader New York: Praeger: 161-9.

Simmel, G. (1908/1950). 'The Quantitative Determination of Group Divisions and of Certain Groups' in K. Wolff (ed., trans.) The Sociology of Georg Simmel New York: Free Press: 105-77.

Turner, B. S. (1990). 'Outline of a theory of citizenship' Sociology, 24, 189-217. http://dx.doi.org/10.1177/0038038590024002002

- (1993). 'Contemporary problems in the theory of citizenship' in Bryan S. Turner (ed.) Citizenship and Social Theory London: Sage: 1-18.

Bryan, S. T. (1997). 'Citizenship Studies: A General Theory' Citizenship Studies, 1(1), 5-18. http://dx.doi.org/10.1080/13621029708420644

Watson, J. D., \& Crick, F. H. C. (1953). A Structure for Deoxyribose Nucleic Acid. Nature, 171, 737-738. http://dx.doi.org/10.1038/171737a0

White, R. (2002). 'The life of class: A case-study in a sociological concept' Journal of Sociology.

White, R. D., \& Donoghue, J. (2003). Marshall, Mannheim and contested citizenship. British Journal of Sociology, 54(3), 391-406. http://dx.doi.org/10.1080/0007131032000111884 


\section{Appendix}

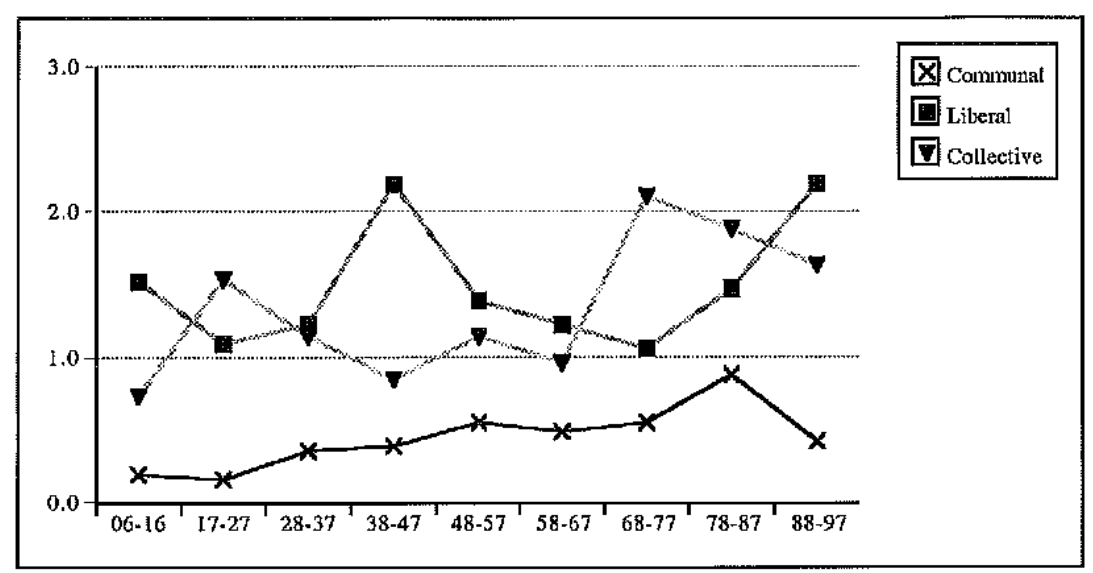

Figure 4. Use of Liberal, Collective and Communal

Table 1. APSA Presidents 1906 to 1997 use of word citizen \& participation

\begin{tabular}{|c|c|c|c|c|c|}
\hline President & Citizen & Participation & President & Citizen & Participation \\
\hline 1906/Shaw & 3 & 2 & 1952 & & \\
\hline 1907/Judson & 7 & 0 & 53/Hearing & 10 & 2 \\
\hline 1908/Bryce & 6 & 0 & 54/Bunche & 5 & 1 \\
\hline 1909/Lowell & 2 & 0 & 55/McKinley & 2 & 0 \\
\hline 1910/Wilson & 0 & 0 & 56/Lasswell & 1 & 1 \\
\hline 1911/Baldwin & 6 & 0 & 57/Schattshneider & 0 & 0 \\
\hline 1912/Hart & 3 & 0 & 58/Key & 0 & 0 \\
\hline 1913/Willoughby & 6 & 0 & 59/Cole & 4 & 2 \\
\hline 1914/Moore & 1 & 0 & 60/Swisher & 1 & 3 \\
\hline 1915/Freund & 0 & 0 & 61/Redford & 2 & 0 \\
\hline \multirow[t]{2}{*}{ 1916/Lacy } & 6 & 1 & 62/Hyneman & 4 & 0 \\
\hline & & & 63/Friedrich & 15 & 20 \\
\hline 1917/Smith & 3 & 2 & 64/Pritchett & 3 & 2 \\
\hline 1918 & & & 65/Truman & 1 & 0 \\
\hline 1919/Ford & 0 & 1 & 66/Almond & 0 & 1 \\
\hline 1920 & & & 67/Dahl & 65 & 53 \\
\hline 1921/Rowe & 0 & 1 & 68/Fainsod & 1 & 0 \\
\hline 1922/Dunning & 2 & 1 & 69/Easton & 0 & 1 \\
\hline 1923/Garfield & 1 & 0 & 70/Deutsch & 1 & 1 \\
\hline 1924/Garner & 2 & 0 & 71/Lane & 0 & 0 \\
\hline 1925/Merriam & 0 & 0 & 72/Eulau & 2 & 9 \\
\hline 1926/Beard & 2 & 0 & 73/Ward & 0 & 1 \\
\hline 1927/Munro & 16 & 0 & 74/Leiserson & 7 & 9 \\
\hline 1928/Reeves & 1 & 0 & 75/Ranney & 3 & 0 \\
\hline 1929/Fairlie & 0 & 0 & & & \\
\hline 1930 & & & 76/B urns & 0 & 4 \\
\hline 1931/Corwin & 0 & 0 & 77/Beer & 5 & 2 \\
\hline 1932/Willoughby & 1 & 0 & 78/Wahike & 1 & 3 \\
\hline 1933/Loeb & 2 & 1 & 79/Epstein & 2 & 3 \\
\hline 1934/Shepard & 3 & 0 & 80/Miller & 2 & 6 \\
\hline 1935/Coker & 3 & 0 & 81/Lindblom & 6 & 0 \\
\hline 1936/Holcombe & 1 & 0 & 82/Lipset & 10 & 5 \\
\hline 1937/Powell & 0 & 4 & 83/Riker & 0 & 2 \\
\hline 1938/Dykstra & 4 & 1 & 84/Converse & 8 & 2 \\
\hline 1939/Haines & 2 & 1 & 85/Fenno & 2 & 1 \\
\hline
\end{tabular}




\begin{tabular}{cccccc} 
1940/Brooks & 8 & 1 & 86/Wildaysky & 6 & 5 \\
1941/Ogg & 0 & 2 & 87/Huntington & 0 & 6 \\
1942/Anderson & 18 & 2 & 88/Waltz & 0 & 0 \\
1943/Cushman & 2 & 1 & 89/Pye & 3 & 0 \\
1944/White & 4 & 3 & 90/Shklar & 16 & 1 \\
1945/Gaus & 7 & 4 & $91 /$ Lowi & 1 & 2 \\
1946/Dodd & 10 & 0 & $92 /$ Wilson & 0 & 0 \\
1947/MacMahon & 1 & 1 & 93/Barker & 0 & 3 \\
1948/Spencer & 4 & 2 & $94 /$ Jones & 1 & 5 \\
1949/Wright & 7 & 0 & $95 /$ Verba & 43 & 34 \\
1950/Pollock & 9 & 6 & $96 /$ ijphart & 23 & 55 \\
1951/0degard & 2 & 0 & 97/Ostrom & 13 & 10 \\
& & & Total & $\mathbf{8 8}$ & \\
\hline
\end{tabular}

\section{$(\infty)$ EY}

This work is licensed under a Creative Commons Attribution 3.0 License. 